LA-UR-96- 3185 CONF-960850--5

Title:

Magnetic Field and Field Orientation Dependence of the Critical Current Density in Bi-2212 Round Wires and Other HTS Conductors

Author(s):

J.O. Willis, STC

T.G. Holesinger, MST-6

J.Y. Coulter, STC

M.P. Maley, STC

Applied Superconductivity Conference

Pittsburgh, PA

August 26-30, 1996

DISTRIBUTION OF THIS DOCUMENT IS UNLLMTEOS ho MASTER

Los Alamos National Laboratory, an affirmative action/equal opportunity employer, is operated by the University of California for the U.S. Department of Energy under contract W-7405-ENG-36. By acceptance of this article, the publisher recognizes that the U.S. Government retains a nonexclusive, royalty-free license to publish or reproduce the published form of this contribution, or to allow others to do so, for U.S. Government purposes. The Los Alamos National Laboratory requests that the publisher Identify this article as work performed under the auspices of the U.S. Department of Energy. 


\section{DISCLAIMER}

Portions of this document may be illegible in electronic image products. Images are produced from the best available original document. 


\section{DISCLAIMER}

This report was prepared as an account of work sponsored by an agency of the United States Government. Neither the United States Government nor any agency thereof, nor any of their employees, makes any warranty, express or implied, or assumes any legal liability or responsibility for the accuracy, completeness, or usefulness of any information, apparatus, product, or process disclosed, or represents that its use would not infringe privately owned rights. Reference herein to any specific commercial product, process, or service by trade name, trademark, manufacturer, or otherwise does not necessarily constitute or imply its endorsement, recommendation, or favoring by the United States Government or any agency thereof. The views and opinions of authors expressed herein do not necessarily state or reflect those of the United States Government or any agency thereof. 


\title{
Magnetic Field and Field Orientation Dependence of the Critical Current Density in Bi-2212 Round Wires and other HTS ConductorRECEIVED
}

\author{
J.O. Willis, T.G. Holesinger, J.Y. Coulter, and M.P. Maley \\ Superconductivity Technology Center, MS-K763, Los Alamos National Laboratory, NM 87545 USA
}

SEP 231996

\begin{abstract}
We have performed measurements of the magnetic field dependence of the critical current density $J_{c}$ of $\mathrm{Bi}-2212 / \mathrm{Ag}$ round wire produced by isothermal melt processing. In contrast to the case for flat tape, there is very little dependence of $J_{c}$ on the direction of the magnetic field as it is rotated normal to the wire axis, which is the direction of the nominal current flow. However, when the angle of the magnetic field direction is rotated from normal to the wire axis to parallel to that axis, $J_{c}$ at $64 \mathrm{~K}$ and $0.2 \mathrm{~T}$ increases by more than a factor of four. Again, this is in contrast to the results observed for Bi-2212/Ag and Bi-2223/Ag flat tapes, which show no anisotropy under similar experimental conditions. We can explain these differences in angular anisotropy by referring to the microstructure of these two conductor types, which have distinctly different types of grain alignment. We discuss the general behavior of the dependence of $J_{c}$ on the orientation of a magnetic field for high temperature superconductors.
\end{abstract}

\section{INTRODUCTION}

Low temperature superconductor conductors are typically prepared in the form of round wires. For high temperature superconductors (HTS), the most favorable geometry for the conductor is a flat, highly aspected tape made using $\mathrm{Bi}_{2} \mathrm{Sr}_{2} \mathrm{CaCu}_{2} \mathrm{O}_{\mathrm{y}}(\mathrm{Bi}-2212)$ or $(\mathrm{Bi}, \mathrm{Pb})_{2} \mathrm{Sr}_{2} \mathrm{Ca}_{2} \mathrm{Cu}_{3} \mathrm{O}_{\mathrm{y}}$ (Bi-2223) by the powder-in-tube (PIT) process [1]. A silver or silver alloy tube is filled with the HTS powder or precursor powder; the tube is then sealed, extruded or drawn to wire, and then rolled to flat tape with typical dimensions $0.1-0.2 \mathrm{~mm}$ thick and $2-3 \mathrm{~mm}$ wide. Alternatively, wire is hex-drawn, restacked into another Ag tube, redrawn, and rolled to form multifilament tape. The tape is then subjected to a heat treatment to form the superconductive phase, achieve grain growth, and a high density, continuous path for current flow. For $\mathrm{Bi}-2223$, one or more additional deformation and heat treatment steps may follow. The rolling step provides the densification of the HTS core that is necessary for good reactivity and connectivity. As a result of the conductor geometry and HTS filament microstructure (highly conductive $a b$ basal planes aligned parallel to the flat surface of the tape), there is a strong dependence of the critical current density $\mathrm{J}_{c}$ on the angle of an applied magnetic field. This strong anisotropy may cause problems for certain applications. In addition, it is difficult to wind a high homogeneity magnet from flat tape; usually tape is wound into flat "pancake coils" that are then stacked to form a solenoid.

Several approaches to solve the problems resulting from the flat tape geometry have been made. The first is a non-PIT

Manuscript received August 27, 1996.

This work was performed under the auspices of the U.S. Department of Energy, Office of Energy Management. process in which a $\mathrm{Ag}$ sheet is coated with a slurry coldinf the HTS powder, rolled into a round "jelly roll" wire, and finally thermally processed [2]. In the second approach, the PIT method is used but the rolling step is omitted, and round mono- or multifilament wire is the result $[3,4]$. Because these conductors are axially symmetric, there is very little anisotropy in $J_{c}$ when the field direction is rotated about the wire axis. Because the wires are round, they can be easily wound into a solenoid.

In this paper we investigate the anisotropy of $J_{c}$ in round wire for the field direction perpendicular to the wire axis and for the field direction rotating in the plane of the wire, that is, from parallel to perpendicular to the current direction. In this case, anisotropy is observed. We investigate the source of this anisotropy from the perspective of the HTS microstructure. We show why the behavior is different from that observed for flat tape and why it is not the result of Lorentz force free current flow.

\section{EXPERIMENTAL}

Isothermal melt processing (IMP) [5], [6] was used to prepare powder-in-tube Bi-2212 round wire samples with high critical current densities [7]. The melt processing and solidification steps in IMP are carried out at one temperature as the name IMP implies. The process is shown schematically in Fig. 1. First, the superconductor within the wire is melted in an inert atmosphere. Solidification occurs when a suitable oxygen partial pressure is introduced into the system. This is possible because of the strong inverse dependence of the solidus temperature of $\mathrm{Bi}-2212$ on the oxygen partial pressure.

Wires of nominal $1 \mathrm{~mm}$ diameter were prepared by packing splat-quenched powder into a silver tube, sealing the tube and drawing to the final diameter. The fill factor is about $35 \%$. Smaller diameter wires were made by first partially melt processing the $1 \mathrm{~mm}$ diameter wire at $790^{\circ} \mathrm{C}$ for $30 \mathrm{~min}$ in $\mathrm{Ar}$ and then drawing to $0.75 \mathrm{~mm}$ or $0.5 \mathrm{~mm}$ diameter. The wires were then processed in 5 to $18 \mathrm{~cm}$ lengths according to the

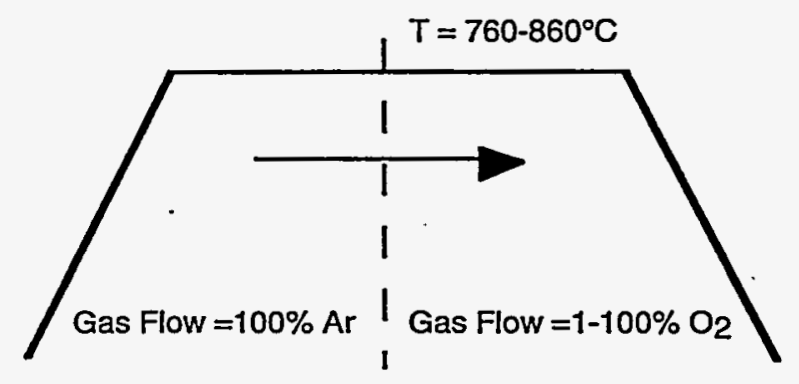

Fig. 1. Schematic of the isothermal melt process (IMP) for preparing the Bi-2212/Ag round wires. 
profile shown in Fig. 1. Critical current $I_{c}$ measurements were performed with a dc transport current and a $1 \mu \mathrm{V} / \mathrm{cm}$ criterion on $4 \mathrm{~cm}$ lengths of the sample immersed in liquid cryogen. Optical and scanning electron microscopy were used to determine the morphology and composition of the $\mathrm{Bi}-2212$ core.

\section{RESULTS AND DISCUSSION}

For each particular oxidizing atmosphere used during IMP, the highest critical currents were found in wires processed between $800^{\circ} \mathrm{C}$ to $820^{\circ} \mathrm{C}$. For a $1 \mathrm{~mm}$ diameter round wire, the highest core $\mathrm{J}_{\mathrm{c}}$ of $4.3 \times 10^{4} \mathrm{~A} / \mathrm{cm}^{2}$ at $4 \mathrm{~K}$ and self-field was obtained by processing at $810^{\circ} \mathrm{C}$ using $27 \% \mathrm{O}_{2} / \mathrm{Ar}$ as the oxidizing atmosphere. The highest core $\mathrm{J}_{\mathrm{C}}$ of $6.2 \times 10^{4} \mathrm{~A} / \mathrm{cm}^{2}$ ( $4 \mathrm{~K}$, self field) was obtained in a $0.75 \mathrm{~mm}$ round wire isothermally processed at $805^{\circ} \mathrm{C}$ in $10 \% \mathrm{O}_{2} / \mathrm{Ar}$ [7].

Shown in Fig. 2 are normalized plots of the critical current as a function of field applied perpendicular to the wire axis measured in boiling liquid helium and liquid neon, respectively. For the liquid He measurements, a $0.75 \mathrm{~mm}$ wire processed at $805^{\circ} \mathrm{C}$ in $10 \% \mathrm{O}_{2} / \mathrm{Ar}$ has $\mathrm{J}_{c}$ 's of $6.2 \times 10^{4}$ $\mathrm{A} / \mathrm{cm}^{2}\left(\mathrm{I}_{\mathrm{c}}=105 \mathrm{~A}\right)$ and $2.7 \times 10^{4} \mathrm{~A} / \mathrm{cm}^{2}\left(\mathrm{I}_{\mathrm{c}}=45 \mathrm{~A}\right)$ at $0 \mathrm{~T}$ and $9 \mathrm{~T}$, respectively. The critical current displays only a small dependence upon the applied field above $2 \mathrm{~T}$. In the case of the liquid Ne temperature measurements, a $1 \mathrm{~mm}$ wire processed at $810^{\circ} \mathrm{C}$ in $27 \% \mathrm{O}_{2} / \mathrm{Ar}$ has a $\mathrm{J}_{\mathrm{c}}$ of $1.9 \times 10^{4} \mathrm{~A} / \mathrm{cm}^{2}$ $\left(I_{C}=57 \mathrm{~A}\right)$ in self field. In contrast to the results in $\mathrm{He}$, the $\mathrm{I}_{\mathrm{C}}$ of the $1 \mathrm{~mm}$ wire decreases exponentially with field to $9 \mathrm{~T}$.

Fig. 3 shows the results of anisotropy measurements on a Bi-2212 $0.75 \mathrm{~mm}$ diameter wire carried out in two modes. In mode I, the applied field is rotated such that it is always perpendicular to the wire axis and therefore always perpendicular to the current flow. This is the field orientation a round wire would experience within a solenoidal winding, one of the best applications for this conductor type. The result of the measurement is that there is no dependence on the field direction. In mode II, the magnetic field is initially applied perpendicular to the wire axis, and a rotation of $90^{\circ}$

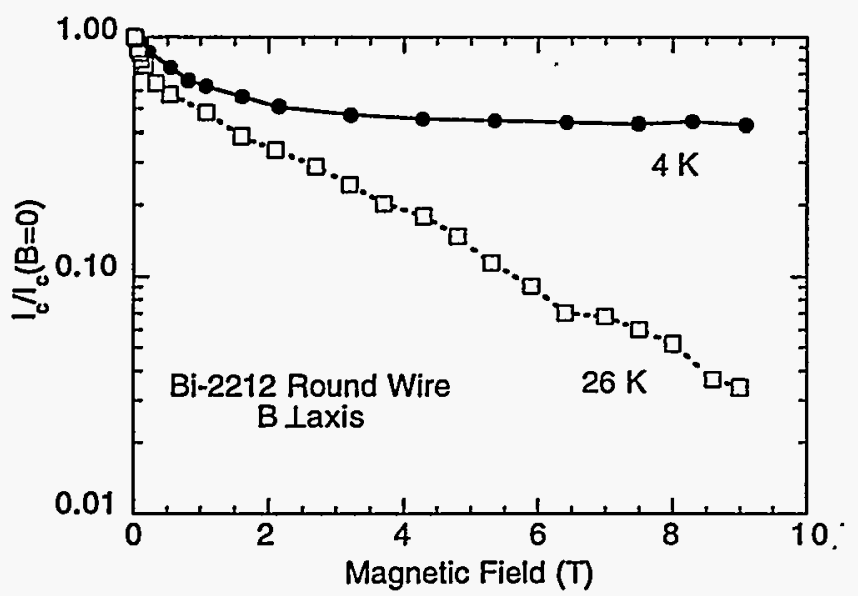

Fig. 2. Plot of normalized critical current $I_{C} / I_{C}(B=0 T)$ as a function of magnetic field applied perpendicular to the wire axis for $\mathrm{Bi}-2212$ monocore round wires. Data at $4 \mathrm{~K}$ are for a $0.75 \mathrm{~mm}$ diam wire and at $26.2 \mathrm{~K}$, for a $1 \mathrm{~mm}$ diam wire.

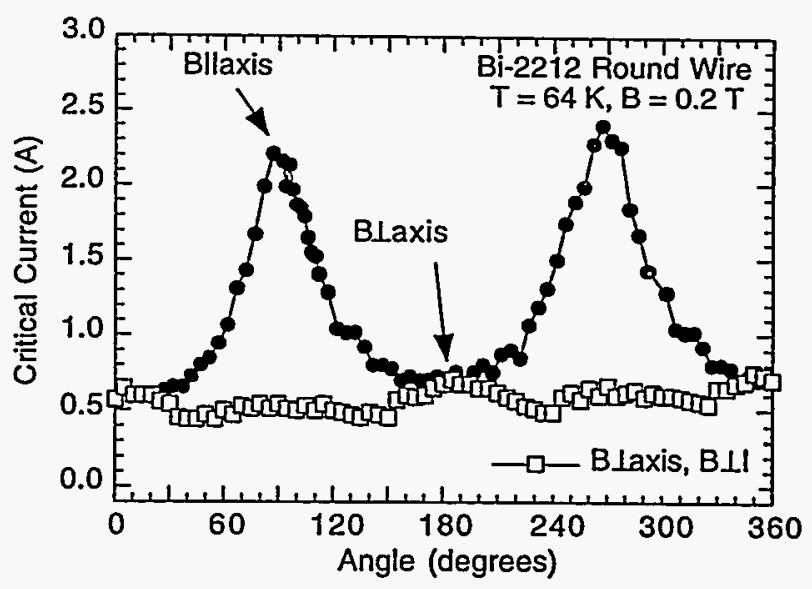

Fig. 3. Anisotropy of a Bi-2212 monocore $0.75 \mathrm{~mm}$ diameter wire at $64 \mathrm{~K}$ in an applied field of $0.2 \mathrm{~T}$. For mode I (open squares), the field is rotated about the normal to the wire axis, and there is only a very small variation in $I_{c}$. For mode II, the field is rotated from perpendicular to the wire axis $\left(0^{\circ}\right)$ to parallel to the wire axis $\left(90^{\circ}\right)$ with an anisotropy of 4-5.

brings the applied field parallel to the wire axis. For this case, there is a moderate anisotropy of a factor of 4 to 5 with the maximum when the field is parallel to the wire axis. The size of the anisotropy increases with increasing magnetic field and temperature.

The structure of these wires consists of regularly spaced, large pores along the length of the wire. This porosity is a result of the relatively low density, compared to that of a rolled tape, of the Bi-2212 core before melt processing. (Lower porosity can be achieved in a multifilament wire [3].) The microstructure of a typical wire, shown in Fig. 4, reveals that there are two types of grain alignment in the wire. In a narrow region within $30-50 \mu \mathrm{m}$ of the $\mathrm{Ag} /$ core interface, the grains of Bi-2212 are aligned parallel to the interface. Farther away from the interface, the grain colonies are more randomly aligned, although the $c$ axes of these colonies do appear to align perpendicularly to the axis of the wire in a fiber texture. This type of microstructure is consistent with the anisotropy data of Fig. 3, which shows a peak in $I_{C}$ as a function of

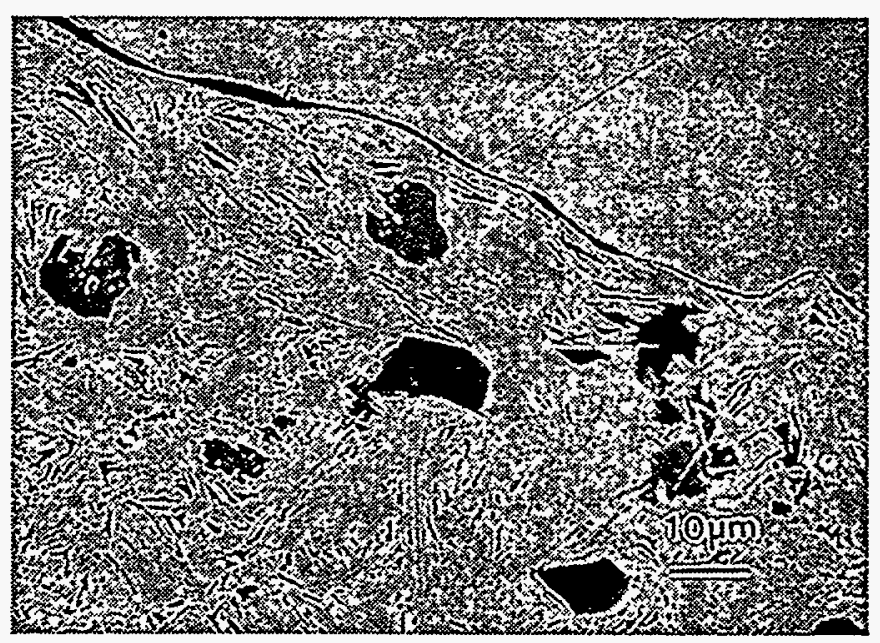

Fig. 4. Cross-sectional backscattered electron micrograph of a $1 \mathrm{~mm}$ $\mathrm{Bi}-2212$ wire. This wire was isothermally melt processed at $810^{\circ} \mathrm{C}$ using $27 \% \mathrm{O}_{2} / \mathrm{Ar}$ as the oxidizing atmosphere. The upper right corner is the Ag sheath. Bi-2212 grains are well aligned within a distance of 30 to $50 \mathrm{~nm}$ of the $\mathrm{Ag}$ interface. 
angle when the applied field is parallel to the wire axis and hence, parallel to the crystallographic $a b$ planes of the B-2212 grains. This increase in $I_{c}$ when the field is parallel to the current flow is not related to the absence of the Lorentz force (the vector product of I and B). Instead it can easily be accounted for by the intrinsic crystallographic anisotropy of $I_{c}$ in $\mathrm{Bi}-2212$. Single crystal films of $\mathrm{Bi}-2212$ show anisotropy ratios $\mathrm{J}_{\mathrm{c}}(\mathrm{B} \| a b) / \mathrm{J}_{\mathrm{c}}(\mathrm{B} \| c)$ at $64 \mathrm{~K}$ and $0.1 \mathrm{~T}$ and $0.2 \mathrm{~T}$ of 30 and 500 , respectively [8]. Furthermore, the spread in the grain angle orientation always yields a component of $B$ perpendicular to the local current flow direction, which is along ab planes. Therefore, even if the average current direction were such as to result in a Lorentz force-free configuration, on a microscopic scale there is always a Lorentz force component acting on the vortex lines.

The absence of a Lorentz force free configuration may be more clearly seen by examining the anisotropy of $I_{c}$ in a $\mathrm{Bi}-2212 / \mathrm{Ag}$ or $\mathrm{Bi}-2223 / \mathrm{Ag}$ sheath tape. In such tapes, the grains are highly aspected, and their $a b$ planes lie preferentially parallel to the large flat areas of the Ag interface and therefore roughly parallel to the plane of the tape. Because there are many grains and the orientation is never perfect, there is a distribution of grain orientations about the mean with.a full width half maximum for $\mathrm{Bi}-2223 / \mathrm{Ag}$ tapes of 10 $20^{\circ}$ [9]. This width is somewhat smaller for $\mathrm{Bi}-2212 / \mathrm{Ag}$ tapes, because of the different growth morphology during the partial melt processing of this material. In Fig 6, the crystallographic anisotropy of a $\mathrm{Bi}-2223 / \mathrm{Ag}$ sheathed tape is evident; for the field along the tape normal (parallel to the $c$ axis for well aligned grains), the $I_{c}$ at $0.6 \mathrm{~T}$ is more than a factor of 30 smaller than when the magnetic field is in the tape plane (parallel to the $a b$ planes of well-aligned grains). However, when the magnetic field direction is rotated in the plane of the tape (top three overlapping curves in Fig. 6), there is no anisotropy. The small residual deviations that are seen in the figure are a result of limitations in the experimental apparatus in fixing the second degree of rotational freedom. These results are consistent with the standard models of current flow, i.e., the modified "brick wall" model [10] and the "railway switch" models [11], for the crystallographically highly anisotropic materials, such as

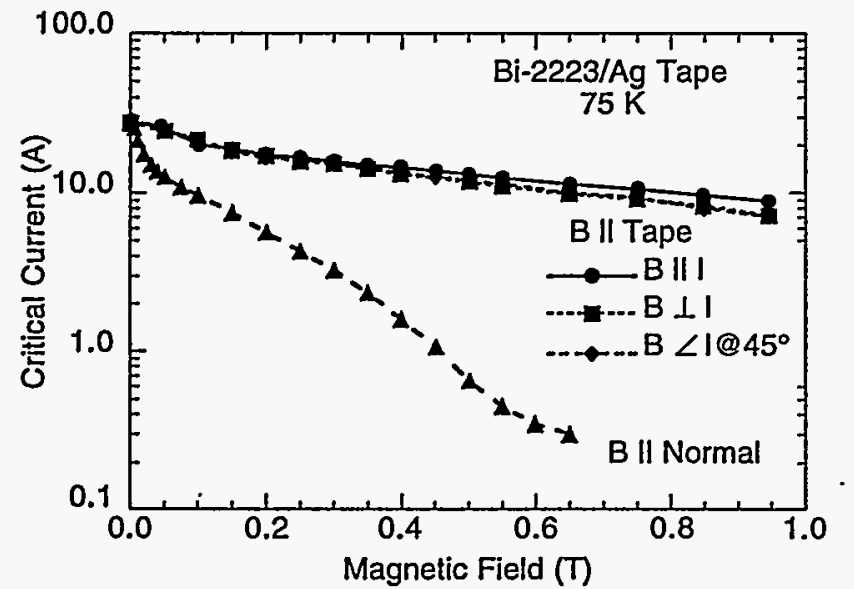

Fig. 5. Critical current density at $75 \mathrm{~K}$ as a function of magnetic field for several field orientations for a multifilament $\mathrm{Bi}-2223 / \mathrm{Ag}$ tape.
$\mathrm{Bi}-2212, \mathrm{Bi}-2223, \mathrm{Tl}-2212$, and $\mathrm{Tl}-2223$. In these models, the current does not flow along streamlines, but rather along a tortuous path seeking to flow along $a b$ planes (the high- $\mathrm{J}_{\mathrm{c}}$ direction) of well-connected grains. In this manner, even for an applied field parallel to the nominal current direction, there is always a component of microscopic current flow perpendicular to the field direction, and therefore there is always a Lorentz force acting in these materials. Thus, there is no enhancement in $I_{c}$ for the field parallel the current direction, as shown in Fig. 6.

There are, however, examples of a true Lorentz force free current flow in single crystal and thin film samples that are nearly single crystals. Early measurements on Bi-2223 thin films ( $0.1 \mu \mathrm{m}$ thick) produced by metalorganic chemical vapor deposition on $\mathrm{LaAlO}_{3}$ substrates showed enhancements in $\mathrm{J}_{\mathrm{c}}$ at $14 \mathrm{~T}$ of $2-3$ for $\mathrm{J}_{\mathrm{c}}(\mathrm{B} \| \mathrm{I}) / \mathrm{J}_{\mathrm{c}}(\mathrm{B} \perp \mathrm{N})$ with Bllab plane for both cases [12]. This anisotropy was observed for both a high quality, single phase film with $\mathrm{J}_{\mathrm{c}}(77 \mathrm{~K}, 0 \mathrm{~T})$ of $0.1 \mathrm{MA} / \mathrm{cm}^{2}$ and for a mixed phase film of half this $\mathrm{J}_{\mathrm{c}}$.

More recently, another demonstration of strong in plane anisotropy and a Lorentz force free current flow was shown for a Y-123 film on a polycrystalline $\mathrm{Ni}$ alloy substrate with an intermediate buffer layer of yttrium stabilized zirconia (YSZ) made by ion beam assisted deposition (IBAD) [13]. In this process, the assisting ion gun selectively sputters away YSZ atoms allowing only one crystallographic orientation to remain and thus produces a YSZ buffer layer that has both $c$ axis and in-plane alignment. The buffer layer then acts as a template for epitaxial growth of the Y-123 film produced by pulsed laser deposition. As a result, very high $\mathrm{J}_{\mathrm{c}}$ values have been achieved. The data shown in Fig. 6 are for a $1.2 \mu \mathrm{m}$ thick film patterned with a $330 \mu \mathrm{m}$ wide by $4 \mathrm{~mm}$ long bridge. It has a $\mathrm{J}_{\mathrm{c}}(75 \mathrm{~K}, 0 \mathrm{~T})$ of $1.3 \mathrm{MA} / \mathrm{cm}^{2}$, and $\mathrm{J}_{\mathrm{C}}$ remains above $0.1 \mathrm{MA} / \mathrm{cm}^{2}$ for fields as large as $4 \mathrm{~T}$ parallel to the $c$ axis and as large as $9 \mathrm{~T}$ parallel to the $a b$ plane. For the Lorentz force free configuration, there is an additional enhancement in $J_{c}$, or in other words, a reduced field dependence. In particular, the large $\sim \mathrm{X} 3$ drop in $\mathrm{J}_{\mathrm{c}}$ at fields less than $0.5 \mathrm{~T}$ is absent for this orientation; above $0.5 \mathrm{~T}$, the two configurations with the field in the $a b$ plane are approximately parallel out to $9 \mathrm{~T}$.

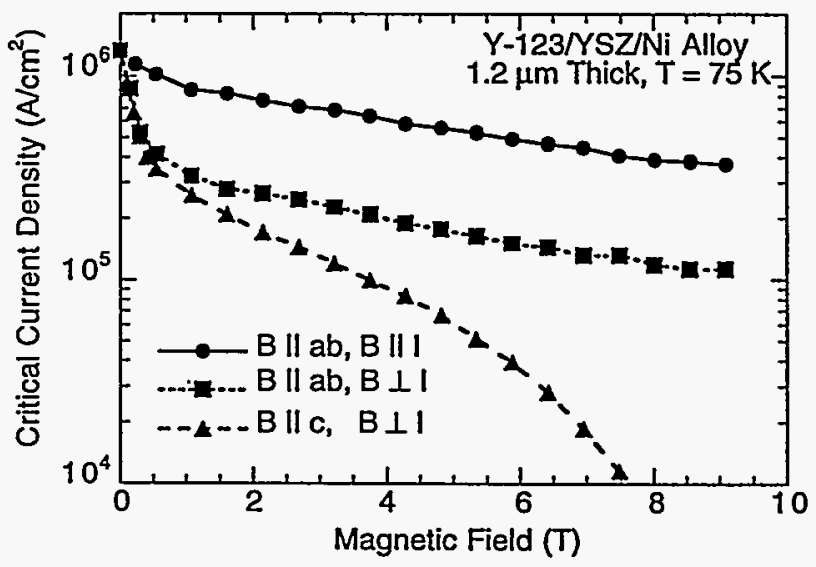

Fig. 6. Critical current density $\mathrm{J}_{\mathrm{c}}$ as a function of applied magnetic field B for a Y-123 film at $75 \mathrm{~K}$. 


\section{SUMMARY}

We have prepared $\mathrm{Bi}-2212 / \mathrm{Ag}$ round wires and have examined the critical current dependence on the magnitude and direction of an applied field. We find that there is no anisotropy when the field is applied perpendicular to the wire axis and rotated about that axis. However, there is a significant $(-X 5)$ increase in $J_{c}$ from the above value when the field is directed along the wire axis; this can be accounted for by the presence of grains aligned with their $a b$ planes parallel to the Ag/core interface and the very large ratio $\mathrm{J}_{\mathrm{c}}(\mathrm{B} \| a b) / \mathrm{J}_{\mathrm{c}}(\mathrm{B} \| c)$ under these conditions. We show that in $\mathrm{Bi}-2212$ and $\mathrm{Bi}-2223 / \mathrm{Ag}$ tapes, because of the electronic anisotropy and polycrystalline morphology of the superconductor, there is always a Lorentz force acting on the microscopic current flow even for the magnetic field direction parallel to the nominal current direction. However, in nearly single crystal films, such as $\mathrm{Y}-123$, there is nonpercolative current flow and a Lorentz force free current flow.

\section{ACKNOWLEDGMENT}

We would like to thank G.N. Riley, Jr. of American Superconductor Corporation for supplying the Bi-2223/Ag tape used in part of this experiment and M.C. Martinez for technical assistance with the $\mathrm{I}_{\mathrm{c}}$ measurements. We would also like to thank all the members of the Bi-2223 Wire Development Group from American Superconductor Corporation, the University of Wisconsin, Argonne and Oak Ridge National Laboratories, and the National Institute of Standards and Technology-Gaithersburg, for useful discussions.

\section{REFERENCES}

[1] K. Heine, J. Tenbrink, M. Thoner, "High-field critical current densities in $\mathrm{Bi}_{2} \mathrm{Sr}_{2} \mathrm{CaCu}_{2} \mathrm{O}_{8+\mathrm{x}}$ wires," Appl. Phys. Lett., vol. 55, pp. 2441-2443, 1989.

[2] M. Mimura, N. Uno, and K. Doi, "Multilayer composite wires of Bi-based superconductor prepared by doctor-blade method," Advances in Superconductivity IV, H. Hayakawa and N. Koshizuka, Eds., Tokyo: Springer-Verlag, 1992, pp. 573-576.
[3] L.R. Motowidlo, G. Galinski, G. Ozeryanski, W. Zhang, and E.E. Hellstrom, "Dependence of critical current density on filament diameter in round multifilament $\mathrm{Ag}$-sheathed $\mathrm{Bi}_{2} \mathrm{Sr}_{2} \mathrm{CaCu}_{2} \mathrm{O}_{\mathrm{x}}$ wires processed in $\mathrm{O}_{2}$, Appl. Phys. Lett., vol. 65, pp. 2731-2733, November 1994.

[4] T. Hase, K. Shibutani, S. Hayashi, M. Shimada, R. Ogawa, Y. Kawate, T. Kiyoshi, and K. Inoue, "Fabrication of double-sheathed Bi-2212 multifilamentary wire," Proceedings of ICECI6/ICMC, May 20-24, 1996, Kitakyushu, Japan, in press.

[5] T.G. Holesinger, D.J. Miller, H.K. Viswanathan, K.W. Dennis, L.S. Chumbley, P.W. Winandy, and A.C. Youngdahl, "Directional isothermal growth of highly textured $\mathrm{Bi}_{2} \mathrm{Sr}_{2} \mathrm{CaCu}_{2} \mathrm{O}_{y} "$ Appl. Phys. Lett., vol 63, pp. 982-984, August 1993.

[6] T.G. Holesinger, D.S. Phillips, J.Y, Coulter, J.O. Willis, and D.E. Peterson, "Isothermal melt processing of Bi-2212 thick films," Physica C, vol. 243, pp. 93-102, February 1995.

[7] T.G. Holesinger, J.M. Johnson, H. Safar, D.S. Phillips, J.Y. Coulter, J.F. Bingert, B.L. Bingham, M.P. Maley, J.L. Smith, and D.E. Peterson, "Isothermal melt processing of $\mathrm{Bi}_{2} \mathrm{Sr}_{2} \mathrm{CaCu}_{2} \mathrm{O}_{y}$ round wire," Physica $C$, vol 253, pp. 182-190, October 1995 .

[8] L. Schmirgeld-Mignot, M.P. Maley, J.Y. Coulter, H. Safar, unpublished.

[9] J.O. Willis, J.Y. Coulter, E.J. Peterson, G.F. Chen, L.L. Daemen, L.N. Bulaevskii, M.P. Maley, G.N. Riley, Jr., W.L. Carter, S.E. Dorris, M.T. Lanagan, and B.C. Prorok, "Dependence of the angular anisotropy of the critical current density on texture in silver-sheathed Bi-2223 tapes," Advances in Cryogenic Engineering, vol 40, R.P. Reed, F.R. Fickett, L.T. Summers, and M. Stieg, Eds., New York: Plenum Press, 1994, pp. 9-16.

[10] L.N. Bulaevskii, L.L. Daemen, M.P. Maley, and J.Y. Coulter, "Limits to the critical current in high-Tc superconducting tapes," Phys. Rev. $B$, vol. 48, pp.13798-13816, Noviember 1993.

[11] B. Hensel, J.-C. Grivel, A. Jeremie, A. Perin, A. Pollini, and R. Flükiger, "A model for the critical current in $(\mathrm{Bi}, \mathrm{Pb})_{2} \mathrm{Sr}_{2} \mathrm{Ca}_{2} \mathrm{Cu}_{3} \mathrm{O}_{\mathrm{x}}$ silver-sheathed tapes," Physica $C$, vol. 205, pp. 329-337, 1993 and Y.H. Li, J.A. Kilner, M. Dhalle, A.D. Caplin, G. Grasso, and R. Flükiger, "'Brick wall' or 'rail switch'-the role of low-angle $a b$-axis grain boundaries in critical current of BSCCO tapes," Supercond. Sci. Technol., vol. 8, pp. 764-768, 1995.

[12] H. Yamasaki, K. Endo, Y. Nakagawa, M. Umeda, S. Kosaka, S. Misawa, S. Yoshida, and K. Kajimura, "Critical current density of high-quality $\mathrm{Bi}_{2} \mathrm{Sr}_{2} \mathrm{Ca}_{2} \mathrm{Cu}_{3} \mathrm{O}_{x}$ thin films prepared by metalorganic chemical-vapor deposition," J. Appl. Phys., vol. 72, pp. 2951-2957, October 1992.

[13] H. Safar, J.Y. Coulter, M.P. Maley, S. Foltyn, P. Arendt, X.D. Wu, and J.O. Willis, "Anisotropy and Lorentz-force dependence of the critical currents in $\mathrm{YBa}_{2} \mathrm{Cu}_{3} \mathrm{O}_{7-\mathrm{d}}$ thick films deposited on nickelalloy substrates," Phys. Rev. B, vol. 52, pp. R9875-R9878, October 1995. 